\title{
Preventable Emergency Hospital Admissions Among Adults With Intellectual Disability in England
}

\author{
Fay J. Hosking, PbD \\ Iain M. Carey, $P b D$ \\ Stephen DeWilde, MD \\ Tess Harris, MD \\ Carole Beighton, MSC \\ Derek G. Cook, PbD
}

Population Health Research Institute, St George's University of London, United Kingdom

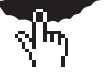

MORE ONLINE

www.annfammed.org
Conflicts of interest: authors report none.

\section{CORRESPONDING AUTHOR}

Iain M. Carey, PhD

Population Health Research Institute St George's University of London London, United Kingdom SW17 0RE i.carey@sgul.ac.uk

\begin{abstract}
PURPOSE Adults with intellectual disabilities experience poorer physical health and health care quality, but there is limited information on the potential for reducing emergency hospital admissions in this population. We describe overall and preventable emergency admissions for adults with vs without intellectual disabilities in England and assess differences in primary care management before admission for 2 common ambulatory care-sensitive conditions (ACSCs).
\end{abstract}

METHODS We used electronic records to study a cohort of 16,666 adults with intellectual disabilities and 113,562 age-, sex-, and practice-matched adults without intellectual disabilities from 343 English family practices. Incident rate ratios (IRRs) from conditional Poisson regression were analyzed for all emergency and preventable emergency admissions. Primary care management of lower respiratory tract infections and urinary tract infections, as exemplar ACSCs, before admission were compared in unmatched analysis between adults with and without intellectual disabilities.

RESULTS The overall rate for emergency admissions for adults with vs without intellectual disabilities was 182 vs 68 per 1,000 per year (IRR $=2.82 ; 95 \% \mathrm{Cl}$, 2.66-2.98). ACSCs accounted for $33.7 \%$ of emergency admissions among the former compared with $17.3 \%$ among the latter (IRR $=5.62 ; 95 \% \mathrm{Cl}, 5.14-6.13)$; adjusting for comorbidity, smoking, and deprivation did not fully explain the difference (IRR $=3.60 ; 95 \% \mathrm{Cl}, 3.25-3.99)$. Although adults with intellectual disability were at nearly 5 times higher risk for admission for lower respiratory tract infections and urinary tract infections, they had similar primary care use, investigation, and management before admission as the general population.

CONCLUSIONS Adults with intellectual disabilities are at high risk for preventable emergency admissions. Identifying strategies for better detecting and managing ACSCs, including lower respiratory and urinary tract infections, in primary care could reduce hospitalizations.

Ann Fam Med 2017;15:462-470. https://doi.org/10.1370/afm.2104.

\section{INTRODUCTION}

A dults with intellectual disabilities experience poorer health outcomes than their peers in the general population and have higher levels of morbidity and mortality. ${ }^{1}$ They also receive poorer-quality health care for a range of reasons including discrimination, communication difficulties, and barriers to access. ${ }^{2}$ Despite international recommendations ${ }^{2,3}$ this group remains largely invisible to routine data collection and analysis. ${ }^{4}$ Acute hospitalization is highly undesirable for individuals with intellectual disabilities, and reducing preventable admissions is particularly important.

Ambulatory care-sensitive conditions (ACSCs) are those for which prevention or effective management in primary care should decrease the risk of acute hospitalization, and they are widely used as an indicator of access to and quality of primary care. ${ }^{5-7}$ Studies of admissions for ACSCs in people with intellectual disabilities have shown that this population consistently has higher rates $;$ however, one relied solely on recording of disability 
during hospitalization, which is incomplete, ${ }^{8}$ and others did not distinguish between acute and planned admissions, thereby including planned admissions that are not preventable in primary care. ${ }^{9}$

We used linkage of primary care records with hospital admission data in England to compare a large unselected group of adults with intellectual disabilities during 2009-2013 with the general population. We report rates of both all emergency (acute) admissions and those only for ACSCs. For 2 common ACSCsurinary tract infection (UTI) and lower respiratory tract infection (LRTI) - that are increasing in the United Kingdom ${ }^{6}$ and for which adults with intellectual disabilities are at high risk, we examined primary care records to ascertain whether preadmission management in primary care differs from that in adults without intellectual disabilities.

\section{METHODS}

\section{Study Design and Setting}

We conducted a retrospective matched cohort study using the Clinical Practice Research Datalink, a large representative primary care database in the United Kingdom, where most (>98\%) of the population uses general (family) practices for primary care services. ${ }^{10}$ Data are entered using Read codes, a hierarchical clinical classification system of approximately 100,000 codes. ${ }^{11}$ We included 343 practices in England recording data on January 1, 2009, with anonymous linkage to hospitalization data. Our study (protocol number 13_094R) was approved by the Independent Scientific Advisory Committee evaluation of protocols of research involving Clinical Practice Research Datalink data. The study sponsor (St George's, University of London) confirmed no further ethical review was required.

\section{Cohort Identification}

We have previously detailed our methodology for identifying adults with intellectual disabilities using Read codes for intellectual disability and associated conditions. ${ }^{12}$ We classified adults with intellectual disabilities as living in a communal setting if they had specific Read codes or if 3 or more people with intellectual disabilities lived at the same address. Additionally, we classified adults with intellectual disability as needing a high level of support if they had a record of severe or profound intellectual disability or, when no record was available (59\% of the sample), if they had 2 or more of the following conditions or factors: cerebral palsy or considerable mobility problems, severe visual impairment, severe hearing impairment, epilepsy, continence problems, or use of percutaneous endoscopic gastrostomy feeding.
The cohort was followed from the latest of January 1 of 2009, January 1 of the year in which they turned 18 years old, or registration date with the practice, until the earliest of death, deregistration, practice cessation of data provision, or study end (March 31, 2013). ${ }^{13}$ For each adult patient with intellectual disabilities, we randomly selected up to 7 contemporary age-, sex-, and practice-matched patients from the remaining population who did not have intellectual disabilities. The average length of follow-up for all individuals was approximately 3 years (1,097 days).

\section{Study Outcomes}

In the United Kingdom, every admission to a National Health Service (NHS) hospital is recorded in Hospital Episodes Statistics, including information on the date, duration, type (eg, emergency), and primary reason for admission (International Classification of Diseases, 10th Revision code). Although information is available regarding multiple episodes of care during each hospitalization, we focused on the initial episode, as it reflected the primary reason for admission. ${ }^{6}$

We included 20 widely used ACSCs, but considered 5 additional conditions relevant to the intellectually disabled population ${ }^{8,14}$ : constipation, aspiration, gastroesophageal reflux disease, osteoporosis, and schizophrenia. We ultimately chose not to include osteoporosis, because it is rarely recorded as the primary reason for admission, or schizophrenia, because of the idiosyncratic recording of elective vs emergency status for many English psychiatric admissions. ${ }^{8}$ This process left 23 ACSCs for study (Supplemental Table 1, available at http://www.annfammed.org/ content/15/5/462/suppl/DC1/).

Because of the high number of admissions for LRTI and UTI, for adults both with and without intellectual disabilities, we used them as exemplar ACSCs to explore primary care use and management before admission. Although epilepsy is a larger contributor to ACSC admissions among adults with intellectuall disability because of its high prevalence, ${ }_{1}^{12}$ its low prevalence among adults without intellectual disabilities makes comparison difficult. For LRTI and UTI admissions, we searched the primary care record 2 weeks before admission to see if there were differences in primary care use between patients with and without intellectual disabilities. Specifically, we sought to determine whether patients had consulted their practice during normal operating hours or whether they had an emergency encounter (emergency department or other out-of-hours service). For those who consulted their practice, we searched for a relevant diagnosis or antibiotic prescription, and for documentation that a urine test had been performed in cases of UTI admission. 


\section{Statistical Analyses}

We present unadjusted and adjusted comparisons of emergency admission rates between patients with and without intellectual disabilities, similar to the methodology used in a previous comparison of mortality rates between the groups. ${ }^{13}$ The unadjusted comparisons already account for differences in the factors on which the groups were matched (age, sex, and practice), while the adjusted comparisons additionally take into account baseline comorbidity, smoking, and deprivation. For comorbidity, we used 9 conditions that are independent predictors of mortality in the general population (atrial fibrillation, cancer, chronic obstructive pulmonary disease, dementia, diabetes, epilepsy, heart failure, severe mental illness, and stroke). ${ }^{15}$ Deprivation was classified by using the Index of Multiple Deprivation, a composite small-area ecologic measure of deprivation based on postcode..$^{16}$

We calculated incident rate ratios (IRRs) for emergency hospitalization using conditional Poisson models
(Stata 12.0, StataCorp LP), stratified on match-sets, with an offset term for follow-up time. Negative binomial models accounting for overdispersion produced more conservative IRRs but did not materially alter our conclusions (data not shown). The examination of primary care use preceding admission was unmatched; we used logistic regression to estimate an odds ratio for patients with vs without intellectual disabilities, adjusting for age and sex.

For analyses of admission rates, we tested for effect modification within 2 of the matched factors (age and sex) and important subgroups (individuals with Down syndrome, in communal residence, or with high support needs) we have identified previously. ${ }^{13}$ For each subgroup comparison, we compared the IRR and confidence intervals derived from each distinct comparison (eg, intellectually disabled patients with Down syndrome vs their matched non-intellectually disabled peers) and calculated $P$ values for betweengroup differences. An alternative approach based on

Table 1. Comparison of All Emergency Admissions Between Adults With and Without ID

\begin{tabular}{|c|c|c|c|c|c|c|c|c|}
\hline \multirow[b]{2}{*}{ Characteristic } & \multicolumn{3}{|c|}{ Adults With ID } & \multirow{2}{*}{$\begin{array}{c}\text { Adults } \\
\text { Without ID } \\
\begin{array}{c}\text { Admission } \\
\text { Rate }^{\text {d }}\end{array}\end{array}$} & \multicolumn{2}{|c|}{ Unadjusted Model ${ }^{b}$} & \multicolumn{2}{|c|}{ Adjusted Modelc } \\
\hline & $\begin{array}{c}\text { Adults, } \\
\text { No. }\end{array}$ & $\begin{array}{l}\text { Admissions, } \\
\text { No. }\end{array}$ & $\begin{array}{c}\text { Admission } \\
\text { Rate }^{d}\end{array}$ & & IRR $(95 \% \mathrm{CI})$ & $\begin{array}{c}P \\
\text { Value }^{e}\end{array}$ & IRR (95\% CI) & $\begin{array}{c}P \\
\text { Value }^{e}\end{array}$ \\
\hline All adults & 16,666 & 9,026 & 182.2 & 67.7 & $2.82(2.66-2.98)$ & - & $2.16(2.02-2.30)$ & - \\
\hline \multicolumn{9}{|c|}{ Stratified by matching factor } \\
\hline Female & 6,989 & 4,250 & 203.8 & 73.5 & $2.90(2.66-3.15)$ & - & $2.09(1.89-2.30)$ & - \\
\hline Male & 9,677 & 4,776 & 166.5 & 63.4 & $2.75(2.55-2.96)$ & .36 & $2.20(2.01-2.41)$ & .45 \\
\hline \multicolumn{9}{|c|}{ Age-group at baseline, y } \\
\hline $18-34$ & 6,981 & 2,374 & 125.3 & 50.5 & $2.54(2.31-2.80)$ & - & $1.81(1.61-2.04)$ & - \\
\hline $35-54$ & 6,283 & 3,201 & 159.3 & 55.6 & $2.96(2.69-3.25)$ & .03 & $2.10(1.87-2.37)$ & .09 \\
\hline $55-84$ & 3,402 & 3,451 & 328.7 & 116.7 & $2.90(2.63-3.19)$ & .06 & $2.43(2.19-2.70)$ & $<.001$ \\
\hline \multicolumn{9}{|c|}{ Stratified by characteristic of adults with ID } \\
\hline \multicolumn{9}{|l|}{ Down syndrome } \\
\hline Yes & 1,793 & 804 & 150.0 & 62.9 & $2.61(2.23-3.05)$ & - & $2.37(1.97-2.84)$ & - \\
\hline No & 14,873 & 8,222 & 186.1 & 68.2 & $2.84(2.68-3.01)$ & .31 & $2.11(1.96-2.26)$ & .27 \\
\hline \multicolumn{9}{|c|}{ Communal accommodation } \\
\hline Yes & 3,392 & 2,141 & 205.7 & 75.0 & $2.91(2.63-3.22)$ & - & $2.15(1.88-2.47)$ & - \\
\hline No & 13,274 & 6,885 & 175.9 & 65.7 & $2.79(2.61-2.98)$ & .50 & $2.16(2.00-2.33)$ & .95 \\
\hline \multicolumn{9}{|c|}{ High level of support needs ${ }^{f}$} \\
\hline Yes & 3,263 & 2,487 & 243.9 & 70.2 & $3.67(3.32-4.05)$ & - & $3.83(3.42-4.28)$ & - \\
\hline No & 13,403 & 6,539 & 166.2 & 67.1 & $2.59(2.42-2.77)$ & $<.001$ & $2.32(2.16-2.49)$ & $<.001$ \\
\hline \multicolumn{9}{|c|}{ ID = intellectual disability; IRR = incidence rate ratio. } \\
\hline \multicolumn{9}{|c|}{ a Matched on age, sex, and practice. } \\
\hline \multicolumn{9}{|c|}{$\begin{array}{l}\text { b IRR from conditional Poisson model for patients with vs without ID. Matched on age, sex, and practice only. } \\
\text { 'Additionally adjusted for comorbidities (atrial fibrillation, cancer, chronic obstructive pulmonary disease, dementia, diabetes, epilepsy, heart failure, severe mental ill- } \\
\text { ness, stroke), Index of Multiple Deprivation quintile, and smoking-for all subgroups except for the subgroup with high support needs, among whom epilepsy was not } \\
\text { used in the adjustment. }\end{array}$} \\
\hline \multicolumn{9}{|c|}{ Admissions per 1,000 adults per year. } \\
\hline \multicolumn{9}{|c|}{ e $P$ values test for difference in IRR between subgroups (for age, $18-34$ years is the comparator group). } \\
\hline \multicolumn{9}{|c|}{$\begin{array}{l}{ }^{\mathrm{f}} \mathrm{Had} \text { been classified as having severe or profound ID by general practitioner or had } 2 \text { or more of the following: epilepsy, cerebral palsy or considerable mobility } \\
\text { problem (wheelchair use or greater impairment), severe visual impairment, severe hearing impairment, a continence problem, or use of percutaneous endoscopic } \\
\text { gastrostomy feeding. }\end{array}$} \\
\hline
\end{tabular}


directly comparing adults with intellectual disabilities (eg, Down syndrome vs no Down syndrome) produced identical conclusions (data not shown).

\section{RESULTS}

\section{Emergency Admissions}

Of the 16,666 adults with intellectual disabilities (mean age $=39.9$ years, $41.3 \%$ male) identified, 3,847 (23.1\%) had an emergency admission during follow-up, with 1,809 (10.9\%) having multiple admissions. These values were much higher than those among the 113,562 age-, sex-, practice-matched adults without intellectual disabilities, of whom $11.9 \%$ had at least 1 emergency hospitalization and $3.8 \%$ had multiple admissions. Of the 3,847 intellectually disabled adults admitted to the hospital, only 2,525 (66\%) had their disability recorded in their hospital data.

The overall annual rate for emergency hospitalizations in the intellectually disabled group was 182 per 1,000 adults, representing a nearly 3 times higher rate $(\mathrm{IRR}=2.82 ; 95 \% \mathrm{CI}, 2.66-2.98)$ than that among their matched counterparts (Table 1). The value remained more than double $(\mathrm{IRR}=2.16 ; 95 \% \mathrm{CI}, 2.02-2.30)$ when adjusted for comorbidities, smoking, and deprivation. There was no effect modification by sex: although admission rates were higher for women vs men with intellectual disabilities (204 vs 167 per 1,000 adults per year), there was no significant difference $(P=.36)$ relative to that of matched counterparts not having intellectual disabilities. The disparity for admissions between adults with and without intellectual disabilities was more marked for older age-groups ( $\geq 35$ years). Higher admission rates were seen in intellectually disabled adults who had high support needs (244 per 1,000 adults per year), with the elevated admission rate vs matched counterparts being more marked than that for intellectually disabled adults not having high support needs $(P<.001)$. Rates of admission did not vary significantly by communal living situation or by presence of Down syndrome.

\section{Potentially Preventable Emergency Admissions}

Figure 1 summarizes, by age-group, rates of emergency admissions for any cause and for ACSCs. Overall, admissions for ACSCs for adults with intellectual disabilities accounted for $33.7 \%$ of total emergency admissions, a value that was essentially the same across age-groups. For adults without intellectual disabilities, $17.3 \%$ of emergency admissions were for ACSCs; however, this proportion increased from $12 \%$ in the youngest age-group to $24 \%$ in the oldest.

Characteristics of emergency admissions for ACSCs are summarized in Table 2. The overall rate in the intellectually disabled group was 61.3 per 1,000 adults annually compared with 11.7 for matched counterparts without intellectual disabilities (IRR $=5.62$; $95 \% \mathrm{CI}, 5.14-6.13)$. The most common ACSCs resulting in admission for intellectually disabled adults were convulsions/epilepsy (35.6\%), LRTI (18.6\%), and UTI $(11.4 \%)$, with the biggest relative disparities vs matched peers seen for aspiration (IRR $=86)$ and convulsions/ epilepsy $(I R R=31)$.

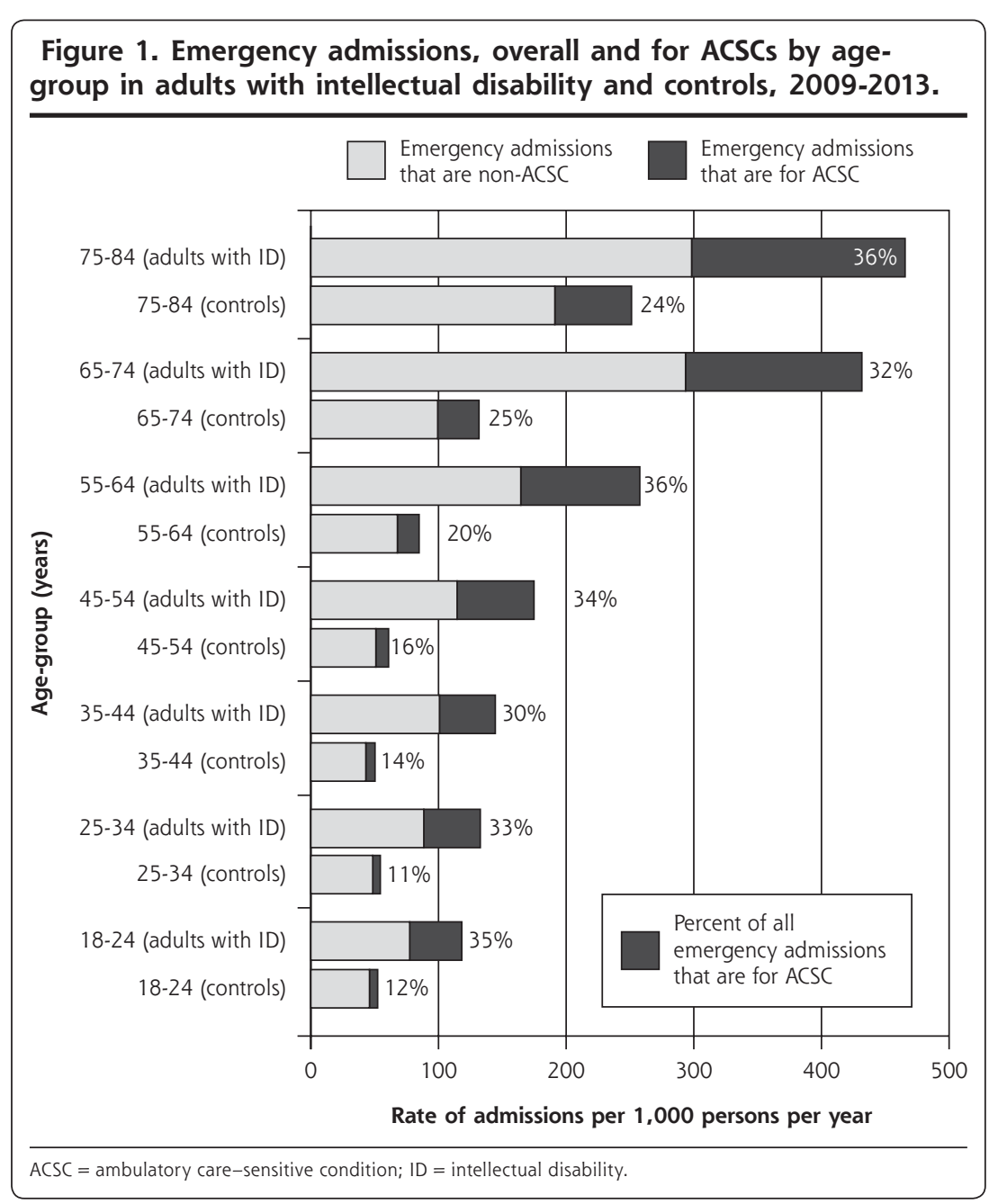


Characteristics of emergency admissions for ACSCs by subgroup, with both unadjusted and adjusted rates, are shown in Table 3. Adults with intellectual disabilities were more than 3 times as likely to have an admission for an ACSC even after their higher comorbidity was accounted for $(I R R=3.60 ; 95 \%$ CI, 3.25-3.99). Although the youngest group of intellectually disabled adults (aged 18 to 34 years) had admission rates more than 7 times higher than those among matched counterparts, this effect modification was explained by comorbidity. Intellectually disabled adults with high support needs were almost 12 times more likely to have had an admission for an ACSC than their matched counterparts $(\mathrm{IRR}=11.78 ; 95 \% \mathrm{CI}, 9.78-14.19)$ after adjustment for comorbidity, which represented a difference compared with those without high support needs $(P<.001)$. Similarly, there was effect modification in admission rates for ACSCs by Down syndrome $(P=.002)$; the higher rate among adults with Down syndrome was largely due to the fact that a sizable proportion (31\%) of ACSC admissions were for pneumonia/LRTI.

\section{Primary Care Use Before Hospitalization for Common Infections}

We compared the pattern of primary care use in the 2 weeks before a UTI admission for 276 adults with intellectual disabilities and 451 adults without intellectual disabilities (Table 4). Intellectually disabled adults were more likely to be male (49\% vs 33\%) and at higher risk for UTI (50\% vs 26\%). Among both patients with and patients without intellectual disabilities, $56 \%$ had a primary care consultation in the 2 weeks leading up to admission (odds ratio $=1.04$; $95 \% \mathrm{CI}, 0.77-1.40)$, with a further $7 \%$ each having an emergency encounter. For those who consulted their practice, there was little difference between groups in recorded UTI diagnoses, urine tests, or antibiotic prescriptions.

Table 2. Comparison of Emergency Admissions for ACSC Between Adults With and Without ID

\begin{tabular}{|c|c|c|c|c|c|}
\hline \multirow[b]{2}{*}{ ACSC } & \multicolumn{2}{|c|}{ Adults With ID } & \multicolumn{2}{|c|}{ Adults Without IDa } & \multirow[b]{2}{*}{ IRR (95\% CI) } \\
\hline & $\begin{array}{l}\text { Admissions, } \\
\text { No. }\end{array}$ & $\begin{array}{l}\text { Admissions, } \\
\text { Rate }^{\mathrm{b}}\end{array}$ & $\begin{array}{l}\text { Admissions, } \\
\text { No. }\end{array}$ & $\begin{array}{l}\text { Admissions, } \\
\text { Rate }^{b}\end{array}$ & \\
\hline Angina & 47 & 1.0 & 329 & 1.0 & $1.00(0.60-1.68)$ \\
\hline Aspiration & 152 & 3.1 & 25 & 0.07 & $85.9(45.3-162.9)$ \\
\hline Asthma & 91 & 1.8 & 233 & 0.7 & $2.84(1.99-4.06)$ \\
\hline Cellulitis & 156 & 3.1 & 331 & 1.0 & $3.31(2.56-4.28)$ \\
\hline Chronic obstructive pulmonary disease & 105 & 2.1 & 454 & 1.3 & $1.68(1.04-2.70)$ \\
\hline Congestive heart failure & 44 & 0.9 & 156 & 0.5 & $2.21(1.44-3.38)$ \\
\hline Constipation & 128 & 2.6 & 142 & 0.4 & $6.79(5.17-8.91)$ \\
\hline Convulsions/epilepsy & 1,081 & 21.8 & 256 & 0.8 & $31.2(24.6-39.5)$ \\
\hline Dehydration and gastroenteritis & 141 & 2.9 & 224 & 0.7 & $4.71(3.60-6.17)$ \\
\hline Dental conditions & 22 & 0.4 & 52 & 0.2 & $2.80(1.67-4.71)$ \\
\hline Diabetes complications & 61 & 1.2 & 140 & 0.4 & $3.26(1.90-5.58)$ \\
\hline Ear, nose, and throat & 28 & 0.6 & 132 & 0.4 & $1.42(0.93-2.17)$ \\
\hline Gangrene & 1 & 0.02 & 10 & 0.03 & - \\
\hline Gastroesophageal reflux disease & 22 & 0.4 & 74 & 0.2 & $2.22(1.35-3.67)$ \\
\hline Hypertension & 3 & 0.06 & 32 & 0.1 & - \\
\hline Influenza & 8 & 0.2 & 18 & 0.05 & - \\
\hline Iron-deficiency anemia & 21 & 0.4 & 40 & 0.1 & $3.97(2.18-7.20)$ \\
\hline Nutritional deficiencies & 0 & 0 & 2 & 0.01 & - \\
\hline Pelvic inflammatory disease & 5 & 0.1 & 26 & 0.08 & - \\
\hline Perforated/bleeding ulcer & 10 & 0.2 & 20 & 0.06 & $3.78(1.63-8.75)$ \\
\hline $\begin{array}{l}\text { Pneumonia and other lower respiratory } \\
\text { tract infections }\end{array}$ & 566 & 11.4 & 772 & 2.3 & $5.59(4.85-6.45)$ \\
\hline $\begin{array}{l}\text { Tuberculosis and other vaccine- } \\
\text { preventable conditions }\end{array}$ & 1 & 0.02 & 11 & 0.03 & - \\
\hline Urinary tract infections & 345 & 7.0 & 528 & 1.5 & $4.76(3.99-5.68)$ \\
\hline Total & 3,038 & 61.3 & 4,007 & 11.7 & $5.62(5.14-6.13)$ \\
\hline
\end{tabular}

$\mathrm{ACSC}=$ ambulatory care-sensitive condition; ID = intellectual disability; IRR = incidence rate ratio.

Note: Estimates for gangrene, hypertension, influenza, nutritional deficiencies, pelvic inflammatory disease, and tuberculosis and other vaccine-preventable diseases were not generated because of insufficient number of admissions.

a Matched on age, sex, and practice.

${ }^{\mathrm{b}}$ Admissions per 1,000 adults per year. 
Table 3. Comparison of Emergency Admissions for ACSCs Between Adults With and Without ID

\begin{tabular}{|c|c|c|c|c|c|c|c|c|}
\hline \multirow[b]{2}{*}{ Characteristic } & \multicolumn{3}{|c|}{ Adults With ID } & \multirow{2}{*}{$\begin{array}{c}\text { Adults } \\
\text { Without ID } \\
\begin{array}{c}\text { Admission } \\
\text { Rate }^{d}\end{array} \\
\end{array}$} & \multicolumn{2}{|c|}{ Unadjusted Model ${ }^{\mathrm{b}}$} & \multicolumn{2}{|c|}{ Adjusted Model ${ }^{\mathrm{c}}$} \\
\hline & $\begin{array}{l}\text { Adults, } \\
\text { No. }\end{array}$ & $\begin{array}{c}\text { Admissions, } \\
\text { No. }\end{array}$ & $\begin{array}{c}\text { Admission } \\
\text { Rate }^{d}\end{array}$ & & IRR (95\% CI) & $\begin{array}{c}P \\
\text { Value }^{c} \\
\end{array}$ & IRR (95\% CI) & $\begin{array}{c}P \\
\text { Value }^{c}\end{array}$ \\
\hline All adults & 16,666 & 3,038 & 61.3 & 11.7 & $5.62(5.14-6.13)$ & - & $3.60(3.25-3.99)$ & - \\
\hline \multicolumn{9}{|c|}{ Stratified by matching factor } \\
\hline \multicolumn{9}{|l|}{ Sex } \\
\hline Female & 6,989 & 1,428 & 68.5 & 13.1 & $5.68(5.03-6.42)$ & - & $3.35(2.87-3.91)$ & - \\
\hline Male & 9,677 & 1,610 & 56.1 & 10.7 & $5.56(4.91-6.30)$ & .81 & $3.89(3.39-4.46)$ & .16 \\
\hline \multicolumn{9}{|c|}{ Age-group at baseline, $y$} \\
\hline $18-34$ & 6,981 & 805 & 42.5 & 6.2 & $7.12(5.96-8.51)$ & - & $3.06(2.47-3.79)$ & - \\
\hline $35-54$ & 6,283 & 1,041 & 51.8 & 8.6 & $6.34(5.43-7.39)$ & .34 & $3.25(2.74-3.87)$ & .67 \\
\hline $55-84$ & 3,402 & 1,192 & 113.5 & 26.2 & $4.56(4.00-5.20)$ & $<.001$ & $4.09(3.52-4.76)$ & .03 \\
\hline \multicolumn{9}{|c|}{ Stratified by characteristic of adults with ID } \\
\hline \multicolumn{9}{|l|}{ Down syndrome } \\
\hline Yes & 1,793 & 392 & 73.1 & 9.3 & $10.00(7.54-13.28)$ & - & $8.28(5.73-11.98)$ & - \\
\hline No & 14,873 & 2,646 & 59.9 & 12.0 & $5.26(4.79-5.77)$ & .001 & $3.21(2.88-3.58)$ & .002 \\
\hline \multicolumn{9}{|c|}{ Communal accommodation } \\
\hline Yes & 3,392 & 915 & 87.9 & 14.0 & $6.86(5.78-8.14)$ & - & $4.98(4.01-6.20)$ & - \\
\hline No & 13,274 & 2,123 & 54.2 & 11.1 & $5.20(4.70-5.76)$ & .01 & $3.35(2.98-3.77)$ & .006 \\
\hline \multicolumn{9}{|c|}{ High level of support needs ${ }^{f}$} \\
\hline Yes & 3,263 & 1,154 & 113.2 & 12.1 & $10.31(8.81-12.07)$ & - & $11.78(9.78-14.19)$ & - \\
\hline No & 13,403 & 1,884 & 47.9 & 11.6 & $4.40(3.95-4.90)$ & $<.001$ & $4.28(3.80-4.81)$ & $<.001$ \\
\hline \multicolumn{9}{|c|}{ ACSC = ambulatory care-sensitive condition; ID = intellectual disability; IRR = incidence rate ratio. } \\
\hline \multicolumn{9}{|c|}{$\begin{array}{l}\text { 'Additionally adjusted for comorbidities (atrial fibrillation, cancer, chronic obstructive pulmonary disease, dementia, diabetes, epilepsy, heart failure, severe mental ill- } \\
\text { ness, stroke), Index of Multiple Deprivation quintile, and smoking-for all subgroups except for the subgroup with high support needs, among whom epilepsy was not } \\
\text { used in the adjustment. } \\
\text { ' Admissions per 1,000 adults per year. } \\
\text { e } P \text { values test for difference in IRR between subgroups (for age, 18-34 years is the comparator group). } \\
\text { f Had been classified as having severe or profound ID by general practitioner or had } 2 \text { or more of the following: epilepsy, cerebral palsy or considerable mobility prob- } \\
\text { lem (wheelchair use or greater impairment), severe visual impairment, severe hearing impairment, a continence problem, or use of percutaneous endoscopic gastros- } \\
\text { tomy feeding. }\end{array}$} \\
\hline
\end{tabular}

For LRTI or pneumonia admissions, in 457 adults with intellectual disabilities and 671 adults without intellectual disabilities, the former were at much higher risk for these infections ( $24 \%$ vs $3 \%$ ). The percentage of intellectually disabled adults consulting their practice in the 2 weeks before admission was marginally higher $(61 \%$ vs $55 \%$, odds ratio $=1.26 ; 95 \% \mathrm{CI}$, $0.99-1.60)$, with a similar percentage (6\%) having an emergency consultation elsewhere. Among those who consulted the practice, recorded diagnoses and antibiotic prescribing were similar between groups.

\section{DISCUSSION}

We have detailed a more than doubling of emergency admissions for adults with intellectual disabilities compared with age-, sex-, practice-matched adults without intellectual disabilities that is not explained by higher levels of comorbidity. Preventable admissions (ie, those for ACSCs) are 5 times more common among intellectually disabled adults. Although the higher prevalence of epilepsy accounts for some of this difference, analysis adjusted for overall comorbidity still suggested that the rate is more than 3 times higher. Despite this higher risk of preventable admissions, we did not detect any notable differences in the primary care use and management before admissions for 2 common ACSCs, urinary tract and lower respiratory tract infections.

\section{Strengths and Limitations}

Our study expands a limited area of research into acute hospitalization of adults with intellectual disabilites. ${ }^{17}$ The main strength of our study is its foundation in a large unselected primary care population of adults with intellectual disabilities, and age-, sex-, and practicematched counterparts without intellectual disabilities. This matching effectively accounts for any differences in regional access to health care and quality or inconsistencies in clinical recording. The linkage between 
Table 4. Comparison of Health Care Use in the 2 Weeks Before Emergency Admission for UTI and for LRTI or Pneumonia, Between Adults With and Without ID

\begin{tabular}{|c|c|c|c|c|}
\hline \multirow[b]{2}{*}{ Characteristic } & \multicolumn{2}{|c|}{ UTI } & \multicolumn{2}{|c|}{ LRTI or Pneumonia } \\
\hline & $\begin{array}{l}\text { Adults With } \\
\text { ID, No. (\%) } \\
\text { (n = 276) }\end{array}$ & $\begin{array}{l}\text { Adults Without } \\
\text { ID, No. (\%) } \\
\text { (n= 451) }\end{array}$ & $\begin{array}{l}\text { Adults With } \\
\text { ID, No. (\%) } \\
\text { (n= 457) }\end{array}$ & $\begin{array}{l}\text { Adults Without } \\
\text { ID, No. (\%) } \\
\text { (n=671) }\end{array}$ \\
\hline \multicolumn{5}{|l|}{ Age-group, $y^{\text {a }}$} \\
\hline $18-34$ & $43(16)$ & $123(27)$ & $84(18)$ & $81(12)$ \\
\hline $35-54$ & $77(28)$ & $115(26)$ & $145(32)$ & $194(29)$ \\
\hline $55-84$ & $156(57)$ & $213(47)$ & $228(50)$ & $396(59)$ \\
\hline Sex, male & $134(49)$ & $150(33)$ & $260(57)$ & $384(57)$ \\
\hline At high risk for infection ${ }^{b}$ & $139(50)$ & $117(26)$ & $108(24)$ & $23(3)$ \\
\hline \multicolumn{5}{|l|}{ Health care use } \\
\hline Consulted primary care practice & $156(56)$ & $251(56)$ & $277(61)$ & $368(55)$ \\
\hline Did not consult but had emergency encounter ${ }^{c}$ & $19(7)$ & $32(7)$ & $27(6)$ & $39(6)$ \\
\hline Had other record of encounter only ${ }^{d}$ & $70(25)$ & $85(19)$ & $97(21)$ & $131(20)$ \\
\hline Did not have any record of use & $31(11)$ & $83(18)$ & $56(12)$ & $133(20)$ \\
\hline \multicolumn{5}{|l|}{ Among those who consulted the practice only } \\
\hline Diagnosis recorded & $22(14)$ & $45(18)$ & $60(22)$ & $80(22)$ \\
\hline Urine test performede & $44(28)$ & $75(30)$ & NA & NA \\
\hline Antibiotics prescribed & $62(40)$ & $115(46)$ & $111(40)$ & $163(44)$ \\
\hline None of the above & $76(49)$ & $118(47)$ & $151(55)$ & $187(51)$ \\
\hline \multicolumn{5}{|l|}{ Among those prescribed antibiotics only } \\
\hline Frontline antibiotic only & $29(47)$ & $57(50)$ & $65(59)$ & $113(69)$ \\
\hline Other antibiotic only & $28(45)$ & $52(45)$ & $32(29)$ & $34(21)$ \\
\hline Both frontline $e^{f}$ and other antibiotic & $5(8)$ & $6(5)$ & $14(13)$ & $16(10)$ \\
\hline \multicolumn{5}{|l|}{ Antibiotics prescribed, No. } \\
\hline 1 & $55(89)$ & $94(82)$ & $88(79)$ & $130(80)$ \\
\hline$\geq 2$ & $7(11)$ & $21(18)$ & $23(21)$ & $33(20)$ \\
\hline \multicolumn{5}{|c|}{ ID = intellectual disability; LRTI = lower respiratory tract infection; NA = not applicable for LRTI or pneumonia; UTI = urinary tract infection. } \\
\hline 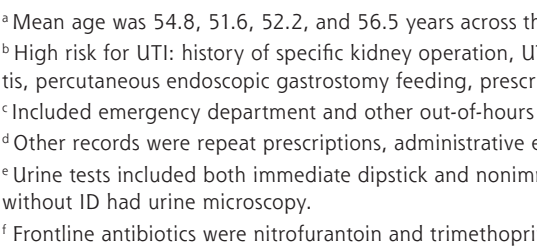 & $\begin{array}{l}\text {, respectively. } \\
\text { heter, or incontine } \\
\text { s for food thickene } \\
\text { es. } \\
\text {, or routine specia } \\
\text { te urine microscop } \\
\text { UTI, and amoxicill }\end{array}$ & $\begin{array}{l}\text { high risk for LRTI or } p \\
\text { r } \geq 2 \text { chest infections ir } \\
\text { appointments. } \\
f \text { those with a test reco } \\
\text { larithromycin, doxycyc }\end{array}$ & history of recurren & $\begin{array}{l}\text { st infections, pneumon } \\
\text { nd } 62(83 \%) \text { of adults } \\
\text { snia or LRTI. }\end{array}$ \\
\hline
\end{tabular}

primary care and hospital data that we used has been called for ${ }^{8,18}$ and allows information from both sources to enhance each other.

The main limitation of our study is the potential for incomplete recording (eg, failure to record urine dipstick tests performed) or inaccurate recording (eg, in a few instances, intellectual disability was erroneously coded as the reason for admission). We also had limited ability to examine epilepsy management, because epilepsy drug and dose changes are mostly initiated and managed in England by non-primary care specialists. Our comparison of primary care use before hospitalization for 2 common infections was an unmatched analysis; given the age and sex differences between patients with and without intellectual disabilities among those seeking care, we cannot be sure how comparable the scenarios are for the 2 groups.

\section{Context}

There are few recent studies of emergency hospital use by adults with intellectual disabilites. ${ }^{19}$ In England, the only previous large-scale national study (20052009) relied solely on the identification of intellectual disabilities from hospital data. ${ }^{8}$ We estimate that approximately 1 in 3 intellectually disabled adults who have an emergency admission in England will not have their disability recorded, and this lapse may explain the small differences in crude ACSC admission rates (intellectual disabilities: 76 per 1,000 per year vs 61 in this study), as milder cases of disability are less likely to be recorded in hospital data. ${ }^{8}$ Although they were unable to calculate population-based admission rates, their estimated relative increase in admissions for ACSCs was similar, at about 5 times higher for adults with intellectual disabilities compared with 
those without. ${ }^{8}$ There have been 3 other large-scale studies on hospitalizations of intellectually disabled adults, but they were unable to differentiate between emergency and planned admissions. ${ }^{9,20,21}$ Our focus on preventable emergency admissions means that any comparison is difficult, as we would not expect good primary care management to decrease planned admissions for ACSCs.

\section{Implications}

Accurate and detailed information on the hospitalization patterns of people with intellectual disabilities is essential for future planning and policy making. ${ }^{22}$ In particular, with increasing life expectancy for this population, ${ }^{23}$ it is essential that preventable admissions are described so that appropriate interventions can be developed. Our work is the first in the United Kingdom to use an unselected group of adults with intellectual disabilities to accurately quantify differences in emergency admissions. Their higher emergency admission rate, which is even more marked for preventable admissions, highlights an area where improvements could be made. We have also highlighted important ACSCs for this group (aspiration, constipation, gastroesophageal reflux disease) that are often absent from general population definitions of ACSC.

More than one-half of those adults with intellectual disabilities admitted for a UTI or a LRTI had visited their primary care practice in the preceding 2 weeks, providing opportunities for management to avoid admissions. Their primary care use and management, however, were not noticeably different from those of patients without intellectual disabilities, even though their primary care records were more likely to identify them as being at high risk for these infections. Integrated risk stratification software is increasingly available in primary care ${ }^{24}$ and could be extended to better incorporate intellectually disabled patients, thereby facilitating the most appropriate initial management ${ }^{25}$ and follow-up monitoring.

Our previous work has identified the potential for improvements in primary care for adults with intellectual disabilities, making sure they see their usual physician when possible and that they are offered longer consultations when necessary..$^{12}$ The introduction of annual health checks by NHS England for this group may be providing other improvements in their quality of care. ${ }^{26}$ Although only about one-half of those eligible currently receive one ${ }^{27}$ we have shown an association between health checks and reduced admissions for ACSCs. ${ }^{28}$ Identifying areas where surveillance could be further improved, together with appropriate treatment reflecting their increased risk and unique health care needs, may therefore improve the overall primary care management of adults with intellectual disabilities and potentially reduce unplanned hospital admissions.

To read or post commentaries in response to this article, see it online at http://www.AnnFamMed.org/content/15/5/462.

Key words: intellectual disability; acute hospitalization; ambulatory care sensitive conditions; primary care; practice-based research

Submitted June 14, 2016; submitted, revised, March 2, 2017; accepted March 27, 2017

Funding support: This project was funded by the National Institute for Health Research (NIHR) Health Services and Delivery Research (HSEDR) Programme (project number 12/64/154).

Disclaimer: The views and opinions expressed herein are those of the authors and do not necessarily reflect those of the HSEDR Programme, NIHR, NHS, or the Department of Health.

Acknowledgments: We would like to acknowledge the dedication and work of the original principal investigator, Dr Sunil M. Shah, who died before the writing of this article, and who, as the principal investigator on this study, successfully led it from inception. We would also like to thank the members of ResearchNet, a service user network for persons with intellectual disability, and the Merton Carers Partnership Group, a group of family carers of adults with intellectual disability linked to the Learning Disability Partnership Board. Their involvement subsequently contributed to the design of the study in terms of choice of outcomes and examination of potential modifying factors, and helped in interpreting and disseminating findings.

Supplementary materials: Available at http://www.AnnFamMed. org/content/15/5/462/suppl/DC1/.

\section{References}

1. Emerson EB, Baines S. Health Inequalities \& People with Learning Disabilities in the UK: 2010. United Kingdom: Improving Health and Lives: Learning Disabilities Observatory; 2010. https://www. choiceforum.org/docs/hi.pdf. Accessed Feb 29, 2016.

2. Michael J. Healthcare for All. Report of the independent inquiry into access to healthcare for people with learning disabilities. London, UK: Department of Health; 2008. http://webarchive.nationalarchives.gov.uk/20130105064250tf_/http://www.dh.gov.uk/en/ Publicationsandstatistics/Publications/PublicationsPolicyAndGuidance/DH_099255. Accessed Oct 15, 2015.

3. Office of the Surgeon General (US), National Institute of Child Health and Human Development (US), Centers for Disease Control and Prevention (US). Closing the Gap: A National Blueprint to Improve the Health of Persons with Mental Retardation: Report of the Surgeon General's Conference on Health Disparities and Mental Retardation. Washington, DC: US Department of Health and Human Services; 2002. http://www.ncbi.nlm.nih.gov/books/NBK44354/. Accessed Apr 29, 2016.

4. Glover G, Emerson E, Baines S. NHS Data Gaps for Learning Disabilities. United Kingdom: Improving Health and Lives: Learning Disabilities Observatory; 2011. http://webarchive.nationalarchives.gov. uk/20160704155744/http://www.improvinghealthandlives.org.uk/ uploads/doc/vid_11422_IHAL2011-06-NHSDataGaps.pdf. Accessed Aug 14, 2017.

5. Purdy S, Griffin T, Salisbury C, Sharp D. Ambulatory care sensitive conditions: terminology and disease coding need to be more specific to aid policy makers and clinicians. Public Health. 2009;123(2): 169-173. 
6. Bardsley M, Blunt I, Davies S, Dixon J. Is secondary preventive care improving? Observational study of 10-year trends in emergency admissions for conditions amenable to ambulatory care. BMJ Open. 2013;3(1):e002007.

7. Billings J, Zeitel L, Lukomnik J, Carey TS, Blank AE, Newman L. Impact of socioeconomic status on hospital use in New York City. Health Aff (Millwood). 1993;12(1):162-173.

8. Glover G, Evison F. Hospital admissions that should not happen. United Kingdom: Improving Health and Lives: Learning Disabilities Observatory; 2013. http://www.ndti.org.uk/uploads/files/lHAL-201302_Hospital_admissions_that_should_not_happen_ii.pdf. Accessed Mar 11, 2015.

9. Balogh R, Brownell M, Ouellette-Kuntz H, Colantonio A. Hospitalisation rates for ambulatory care sensitive conditions for persons with and without an intellectual disability-a population perspective. J Intellect Disabil Res. 2010;54(9):820-832.

10. Herrett E, Gallagher AM, Bhaskaran K, et al. Data Resource Profile: Clinical Practice Research Datalink (CPRD). Int J Epidemiol. 2015; 44(3):827-836.

11. Chisholm J. The Read clinical classification. BMJ. 1990;300(6732): 1092.

12. Carey IM, Shah SM, Hosking FJ, et al. Health characteristics and consultation patterns of people with intellectual disability: a crosssectional database study in English general practice. Br J Gen Pract. 2016;66(645):e264-e270.

13. Hosking FJ, Carey IM, Shah SM, et al. Mortality Among Adults With Intellectual Disability in England: Comparisons With the General Population. Am J Public Health. 2016;106(8):1483-1490.

14. Balogh RS, Ouellette-Kuntz H, Brownell M, Colantonio A. Factors associated with hospitalisations for ambulatory care-sensitive conditions among persons with an intellectual disability: a publicly insured population perspective. J Intellect Disabil Res. 2013;57(3): 226-239.

15. Carey IM, Shah SM, Harris T, DeWilde S, Cook DG. A new simple primary care morbidity score predicted mortality and better explains between practice variations than the Charlson index. J Clin Epidemiol. 2013;66(4):436-444.

16. English indices of deprivation 2010. London, England: Department for Communities and Local Government; 2011. https://www.gov.uk/ government/statistics/english-indices-of-deprivation-2010. Accessed Oct 28, 2015.

17. Williamson T, Flowers J, Cooke M. Quantifying emergency department admission rates for people with a learning disability. Emerg Med J. 2012;29(9):771-772.
18. Heslop P, Lauer E, Hoghton M. Mortality in People with Intellectual Disabilities. J Appl Res Intellect Disabil. 2015;28(5):367-372.

19. Morgan CL, Ahmed Z, Kerr MP. Health care provision for people with a learning disability. Record-linkage study of epidemiology and factors contributing to hospital care uptake. Br J Psychiatry. 2000;176:37-41.

20. Ailey SH, Johnson T, Fogg L, Friese TR. Hospitalizations of adults with intellectual disability in academic medical centers. Intellect Dev Disabil. 2014;52(3):187-192.

21. Skorpen S, Nicolaisen M, Langballe EM. Hospitalisation in adults with intellectual disabilities compared with the general population in Norway. J Intellect Disabil Res. 2016;60(4):365-377.

22. Glover G. Numbers and policy in care for people with intellectual disability in the United Kingdom. J Appl Res Intellect Disabil. 2015; 28(1):12-21.

23. Patja K, livanainen $M$, Vesala $H$, Oksanen $H$, Ruoppila I. Life expectancy of people with intellectual disability: a 35-year follow-up study. J Intellect Disabil Res. 2000;44(Pt 5):591-599.

24. Hippisley-Cox J, Coupland C. Predicting risk of emergency admission to hospital using primary care data: derivation and validation of QAdmissions score. BMJ Open. 2013;3(8):e003482.

25. Freund T, Campbell SM, Geissler S, et al. Strategies for reducing potentially avoidable hospitalizations for ambulatory care-sensitive conditions. Ann Fam Med. 2013;11(4):363-370.

26. Buszewicz M, Welch C, Horsfall $L$, et al. Assessment of an incentivised scheme to provide annual health checks in primary care for adults with intellectual disability: a longitudinal cohort study. Lancet Psychiatry. 2014;1(7):522-530.

27. Glover G, Emerson E, Evison F. The Uptake of Health Checks for Adults with Learning Disabilities: 2008/9 to 2011/12. United Kingdom: Improving Health and Lives: Learning Disabilities Observatory; 2012. http://webarchive.nationalarchives.gov. uk/20160704150527/http://www.improvinghealthandlives.org.uk/ uploads/doc/vid_16402_IHAL2012-07\%20Health\%20Checks\%20 for\%20People\%20with\%20Learning\%20Disabilities\%20 2008-9\%20to\%202011-12v3.pdf. Accessed Feb 29, 2016.

28. Carey IM, Hosking FJ, Harris T, et al. Do health checks for adults with intellectual disability reduce emergency hospital admissions? Evaluation of a natural experiment. J Epidemiol Community Health. 2017;71(1):52-58. 